\title{
Understanding the effects of individual attitudes, perceptions, and residential neighborhood types on university commuters' bicycling decisions
}

\author{
Yujin Park \\ City and Regional Planning \\ The Ohio State University \\ park.2329@osu.edu
}

\author{
Gulsah Akar \\ City and Regional Planning \\ The Ohio State University \\ akar.3@osu.edu
}

\begin{abstract}
This study investigates the effects of individual perceptions and residential neighborhoods on university commuters' bicycling decisions using the 2015 Ohio State University Travel Pattern Survey data. We generate eight attitudinal/perceptual components based on the 26 bicycling-related questions that capture detailed perceptions of commuters toward bicycling, neighborhood environments, and residential location choice. We create distinct neighborhood typologies combining land use and socioeconomic characteristics, including population, employment, housing and intersection densities, housing types, median age of housing stock, and median household income. Probit regression models are estimated to assess the effects of sociodemographic, attitudinal/perceptual components and neighborhood types while accounting for the residential self-selection effect. Results show that people residing in different neighborhood types reveal significant attitudinal differences in terms of their conditional willingness to bicycle, and evaluation of bicycle friendliness of neighborhoods and routes. We find that bicyclists are more likely to live in neighborhoods that they perceive as having good-quality for bicycling in terms of access to bicycle facilities and lower traffic levels. Results also show the significant association of neighborhood types with bicycle commuting outcomes. People from medium-density, mixed-use, and suburban single-family neighborhoods are less likely to commute by bicycle as compared to those from highdensity, mixed-use neighborhoods.
\end{abstract}

Keywords: Bicycle commuting, personal attitudes/perceptions, neighborhood typology, residential self-selection, university commuters

\section{Article history:}

Received: June 21, 2017

Received in revised form:

November 14, 2018

Accepted: May 6, 2019

Available online: May 23, 2019

\section{Introduction}

As an active transportation mode, bicycle commuting provides multiple benefits, such as time-saving physical exercise, moderate speeds to reach destinations, flexible departure times and environmental sustainability (Akar, Fischer, \& Namgung, 2013; Buehler \& Pucher, 2012). Despite the extensive research and policy effort by public bodies to encourage bicycling among commuters, the far lower portion it accounts for of all commute trips in U.S. (0.59\%, 2017 American Community Survey) tells us

Copyright 2019 Yujin Park \& Gulsah Akar

http://dx.doi.org/10.5198/jtlu.2019.1259

ISSN: $1938-7849$ | Licensed under the Creative Commons Attribution - Noncommercial License 4.0

The Journal of Transport and Land Use is the official journal of the World Society for Transport and Land Use (WSTLUR) and is published and sponsored by the University of Minnesota Center for Transportation Studies. 
that there are still many reasons that people are reluctant to use bicycles.

Typically, the study of bicycling determinants involves two crucial parts: the built environment and personal attitudes/perceptions. From the perspective of transportation planning, the built environment is an essential source of influence that shapes travelers' utilities that lead to mode choice (Ewing \& Cervero, 2010; Handy, Cao, \& Mokhtarian, 2006; Winters, Brauer, Setton, \& Teschke, 2010). Bicycle is a non-motorized vehicle, which makes it particularly susceptible to the influences of the external environment. A residential neighborhood is an important component of the external environment that is experienced on a daily basis by commuters. It is characterized by a variety of built environment factors, such as population and employment densities and street designs, and also differs in socioeconomic status, such as median income or age (Handy et al., 2006; Zahabi, Chang, Miranda-Moreno, \& Patterson, 2016). While some studies have identified bicycling-inducing neighborhood types as a function of land-use characteristics and transport facilities (for instance, Oliva, Galilea, \& Hurtubia, 2018; Pinjari, Eluru, Bhat, Pendyala, \& Spissu, 2008; Zahabi et al., 2016), commuters' attitudes and psychological perceptions were not jointly taken into consideration in those analyses. As a result, no studies have incorporated attitudinal/perceptual dimensions into the analysis of distinct neighborhood typologies, and their relationships with bicycle commuting choice. Capturing how bicyclists and non-bicyclists think and perceive in detail is important for targeted policy formulation.

Our study addresses this gap in the existing literature by integrating neighborhood typology analysis with detailed attitudinal/perceptual indices specific to bicycling, neighborhood conditions, and residential self-selection. We also explore how these attitudes/perceptions and the self-reported degree of residential self-selection vary between bicyclists and non-bicyclists, and across different neighborhood types. Using data from the 2015 Ohio State University (OSU) Campus Travel Pattern Survey, a total of 26 attitudinal/perceptual questions and 7 indicators of neighborhood land-use and socioeconomic characteristics are used to represent each commuter's bicycling decision in detail. A modelling strategy incorporates sociodemographic, attitudinal and neighborhood factors, while accounting for the residential self-selection effect.

\section{$2 \quad$ Literature review}

Existing literature implies that the decision to commute by bicycle is at the intersection of various individual and environmental factors. Socio-demographics, such as gender and age, and trip characteristics play roles in bicycle commuting (Akar et al., 2013; Porter, Salvo, Perez, Reininger, \& Kohl, 2018; Twaddle, Hall, \& Bracic, 2010). For example, males and/or young individuals are more likely to bicycle to work (Cole-Hunter et al., 2015; Muñoz, Monzón, \& López, 2016; Steinbach, Green, Datta, \& Edwards, 2011). As for trip characteristics, distance has a major impact. If travel distance is quite short, people rather choose walking over bicycling, while for long distances, people may prefer motorized modes (Fernández-Heredia, Monzón, \& Jara-Díaz, 2014). Recently, several studies highlight the effects of changes in socio-demographics and trip characteristics on bicycling decisions (Chatterjee, Sherwin, \& Jain, 2013; Oakil, Ettema, Arentze, \& Timmermans, 2016). Chatterjee et al. (2013) state that life events, such as marriage, child birth, or work-place relocation, bring about deliberation over current travel modes. People may begin or stop bicycling after these turning points.

Important links exist between personal attitudes, perceptions and bicycle commuting (Dill, Mohr, \& Ma, 2014; Fernández-Heredia et al., 2014; Heinen, Maat, \& Van Wee, 2011). There is a consensus that strong recognition of bicycling benefits is positively associated with bicycling decisions, while sensitivity to safety and comfort has negative effects on bicycle use (Heinen et al., 2011; Li, Wang, Yang, \& Ragland, 2013; Wuerzer \& Mason, 2015). Despite a number of studies on the impacts of psychological factors on bicycling, the terms used in these studies, such as pro-bike, convenience, efficiency, or flexibil- 
ity, are often ambiguous and too broad to sufficiently inform practitioners of how bicyclists and nonbicyclists think in detail and what behavior and cognitive aspects the practitioners need to target specifically in policy formulation. Recent studies shed light on the social dimensions of bicycle use (Spotswood, Chatterton, Tapp, \& Williams, 2015; Wang, Akar, \& Guldmann, 2015; Willis, Manaugh, \& El-Geneidy, 2015). Positive images towards biking within a community, e.g., healthy, active, and risktaker images, may help motivate individuals to bicycle (Daley \& Rissel, 2011; Gatersleben \& Appleton, 2007; Verhoeven et al., 2016), whereas negative social images of bicycling and bicyclists, e.g., doley, ${ }^{1}$ greenie, ${ }^{2}$ and subculture for students, tend to act as a significant deterrent for non-bicyclists or beginner bicyclists (Daley \& Rissel, 2011; Damant-Sirois \& El-Geneidy, 2015; Maldonado-Hinarejos, Sivakumar, \& Polak, 2014). Notably, Heinen et al. (2011) argue that the extent that social norms influence bicycling decisions may differ by commute distance. They find that the perceived opinion of others toward bicycling affects bicycling choice only over shorter distances $(<5 \mathrm{~km})$, suggesting that bicycling for longer commutes is likely to be an outcome of one's own attitudes.

In addition to personal attitudes/perceptions, the built environment serves as a critical factor for bicycling behaviors. Among the factors cited in previous studies are population and employment densities, retail density, street connectivity, length of separated bicycle trails, distance to the nearest bicycle trail and/or bicycle lanes, average slope, distance to bicycle parking, and amount of green space nearby (Buehler \& Pucher, 2012; Cole-Hunter et al., 2015; Damant-Sirois \& El-Geneidy, 2015; Ma \& Dill, 2015; Marshall \& Garrick, 2010; Piatkowski \& Marshall, 2015; Schoner, Cao, \& Levinson, 2015; Winters et al., 2010). However, the effects of individual environmental variables and bicycle-related facilities vary from study to study, except for street connectivity (Piatkowski \& Marshall, 2015). For instance, length of bicycle trails near a residential location has not been an effective predictor of bicycling choice in some studies (Cole-Hunter et al., 2015; Ma \& Dill, 2015; Winters et al., 2010). Part of the problem may be attributable to measurement errors where bicycle facilities or the real network perceived by bicyclists are not correctly represented (Dill \& Voros, 2007; Ma \& Dill, 2016).

Another group of studies adopt a cluster approach that integrates several factors involving land-use density, diversity and socioeconomic features (Akar, Chen, \& Gordon, 2016; Cervero \& Kockelman, 1997; Damant-Sirois \& El-Geneidy, 2015; Handy et al., 2006; Harding, Patterson, Miranda-Moreno, \& Zahabi, 2012; Manaugh, Miranda-Moreno, \& El-Geneidy, 2010). Neighborhood typologies combining various land-use and socioeconomic traits can identify residential environments in a study area and help understand which typologies are more likely to be associated with targeted travel outcomes (Manaugh et al., 2010). Harding et al. (2012) state that while the isolated impact of particular built environment measures on travel behavior is small, their combined effects become greater in magnitude and clearer in direction when they are typified with a clustered approach.

The issue of residential self-selection often challenges the statistical association between residential neighborhoods and travel behavior. Residential self-selection refers to the situation where individuals select themselves into certain neighborhoods based on their predetermined preferences for specific modes (Cao, Mokhtarian, \& Handy, 2009; Ettema \& Nieuwenhuis, 2017). If this is the case, these individuals will not constitute a statistically independent sample. Consequently, data collected from these individuals may be biased which in turn may create overestimated parameters for the effects of the built environment (Pinjari et al., 2008). Including individuals' attitudes in models may help control for the influence of residential self-selection, as the process of residential self-selection is fundamentally related to personal preferences (Cao et al., 2009; Handy et al., 2006). Yet, Ettema \& Nieuwenhuis (2017) argue that other

\footnotetext{
${ }^{1}$ Doley is used to describe an old or rusty bicycle rode by people who don't have enough money to purchase a car.

${ }^{2}$ Greenie is a term, often derogatory, to refer to a person who campaigns for protection of the environment.
} 
measures additive to attitudes are needed, since attitude/perceptions and reasons for residential location choice can often be decoupled in reality.

In summary, literature on bicycle commuting accentuates the importance of full models that incorporate four aspects - demographic and trip characteristics, personal attitudes and perceptions, neighborhood types, and residential self-selection. We use this comprehensive approach and test different combinations of these variables to achieve robustness.

This study is based on a subpopulation of general commuters (i.e., university commuters). Although the context might be different, many studies examined travel behavior at university campuses to understand the factors associated with daily travel choices and derive useful implications for general policy making (Akar, Flynn, \& Namgung, 2012; Fernández-Heredia et al. 2014; Gatersleben \& Appleton, 2007). In many cases, large universities serve as major trip attractors for workers and students in their regions. Examining the travel behavior of university commuters may provide an opportunity to understand a large proportion of active transport commuters traveling to a single major destination (Bopp, Kaczynski, \& Wittman, 2011; Rodriguez \& Joo, 2004; Sisson \& Tudor-Locke, 2008; Whalen, Páez, \& Carrasco, 2013). Within this consideration, we use data collected in a large university setting to understand bicycle choice for commuting.

\section{Data and methodology}

\subsection{Data}

This study makes use of the data from the 2015 Campus Travel Pattern Survey of The Ohio State University (OSU). The survey was conducted online from April 27, 2015 to May 11, 2015. We distributed the survey to a stratified random sample of 15,100 faculty, staff, graduate/professional students, and undergraduate students (approximately 15\% of the campus population) by email with survey links to the survey instrument website. We acquired a list of randomly selected email addresses from the University's Human Resources Office (for 7,500 faculty and staff) and the University Registrar's Office (for 7,600 graduate/undergraduate students). We received a total of 1,574 responses (a response rate of $10.4 \%$ ), which corresponds to about $1.7 \%$ of the campus population. Among these 1,574 respondents, we selected the off-campus residents for our analysis purposes $(\mathrm{N}=1,169)$.

The survey questionnaire includes questions on socio-demographic characteristics, individuals' attitudes towards bicycling and their own neighborhood characteristics, commute mode choices and behaviors, perceptions of commuting environments and two intersecting streets nearest to respondents' residential locations. The core questions associated with bicycling travel patterns include 26 bicyclingspecific attitudinal/perceptual questions designed to be answered on a Likert scale of 1 ("strongly disagree") to 5 ("strongly agree"). The final sample size for the empirical models is 677 with correct address records and complete responses to every survey item analyzed. ${ }^{3}$ We dropped those who did not provide their address information (names of two streets crossing close to residential location) as well as those who did not respond to one or more of the attitudinal questions included in the analysis. We did not find any systematic pattern among missing values. Even though the resulting sample size may seem small, it is consistent with other relevant studies on campus commute (for instance, Bopp et al., 2011; Rodriguez \& Joo, 2004; Verplanken, Walker, Davis, \& Jurasek, 2008; Wall, Devine-Wright, \& Mill, 2007). In addition to the data from the campus travel survey, neighborhood socioeconomic characteristics, landuse and street infrastructure data were obtained from the US Census Bureau TIGER system, American Community Survey (ACS) and Census Transportation Planning Product (CTPP) at the TAZ (Traffic

\footnotetext{
${ }^{3}$ Interested readers may contact the corresponding author to request the full survey questionnaire.
} 
Analysis Zone) and census block group level.

Table 1 provides the summary of basic characteristics of survey respondents and the distribution of bicyclists across university affiliation (faculty, staff, and students), gender, commute distance, age and their responses to the question on residential self-selection ("Bicycling conditions were a factor in choosing where I live."). Respondents were asked to state the number of times per week they commute to campus by bicycle. The available options were: Never, 1-2 days a week, 3-4 days a week, and 5 or more days a week. A bicyclist in this study is defined as one who commutes to campus by bicycle once or more times per week. Based on this classification, $12.6 \%$ of the analysis sample is classified as bicyclists. This relatively high bicycling rate in our sample is partly due to the definition of a bicyclist in our study. If we present the primary mode of transportation to campus (i.e., the most frequently used mode), the bicycling mode share decreases to $5.4 \%$. Similar bicycle mode-share percentages are reported in relevant studies on campus populations (Akar et al., 2013; Motoaki \& Daziano, 2015).

The definition of being a bicyclist used in this study is in line with many previous studies on active transportation (Daley \& Rissel, 2011; Gatersleben \& Appleton, 2007; Maldonado et al., 2014; Sisson \& Tudor-Locke, 2008; Wuerzer \& Mason, 2015). Even though an ideal situation would be to recognize bicycling frequencies, we could not implement this, because dividing the group of bicyclists into smaller subgroups was not desirable given our sample size. In this study, we segment the population into two (those who ride at least once a week, and others) because we think those who ride once or more bring at least some level of bicycling experience. According to the definition, $33.3 \%$ of those who live within a mile of campus are bicyclists and $24.6 \%$ of those within 5 miles of campus are bicyclists. This percentage gets gradually lower as commute distance gets longer. Notably, about $19.3 \%$ of the respondents agreed with the statement concerning residential self-selection. About $35 \%$ of those who agreed with the statement and $60 \%$ of those who strongly agreed with the same statement are found to be bicycle commuters.

As one of the largest employers in a region, a university sample contains diverse groups. In our survey, however, the response rate of students was rather low, given the proportion of students in the university population. This might have reduced the overall number of bicyclists in our sample. Students are more likely to use active transportation because they tend to live closer to campus, often have to move between classes, and are less likely to afford cars or parking fees. For these reasons, we control for the different university affiliation and commute distance in our statistical models to account for these implicit differences. As suggested in the literature, using social status or demographic variables as dummy variables in models helps deal with the issues related to over/under represented samples instead of introducing weights, as this approach allows to estimate different effects of each categorical group with respect to a dependent variable (DuMouchel \& Duncan, 1983; Winship \& Radbill, 1994). Attaching higher weights to sample populations with fewer observations increases the standard errors of the estimation. 
Table 1. Descriptive statistics of the survey respondents

\begin{tabular}{|c|c|c|c|c|}
\hline & $\mathrm{N}$ & $\%$ & $\begin{array}{c}\text { Bicyclist } \\
(\%)\end{array}$ & $\begin{array}{c}\text { Non-Bicyclist } \\
(\%)\end{array}$ \\
\hline All Respondents & 677 & 100 & 12.6 & 87.4 \\
\hline \multicolumn{5}{|l|}{ University Affliation } \\
\hline Faculty & 237 & 35.0 & 16.9 & 83.1 \\
\hline Staff & 306 & 45.2 & 5.2 & 94.8 \\
\hline Graduate Student & 93 & 13.7 & 20.4 & 79.6 \\
\hline Undergraduate Student & 41 & 6.1 & 24.4 & 75.6 \\
\hline \multicolumn{5}{|l|}{ Gender } \\
\hline Male & 281 & 41.5 & 19.2 & 80.8 \\
\hline Female & 396 & 58.5 & 7.8 & 92.2 \\
\hline \multicolumn{5}{|l|}{ Commute Distance } \\
\hline Less than a mile & 36 & 5.3 & 33.3 & 66.7 \\
\hline 1 to 5 miles & 236 & 34.9 & 24.6 & 75.4 \\
\hline 6 to 10 miles & 159 & 23.5 & 6.3 & 93.7 \\
\hline More than 10 miles & 246 & 36.3 & 3.3 & 96.7 \\
\hline \multicolumn{5}{|l|}{ Age } \\
\hline Under 25 & 102 & 15.1 & 19.6 & 80.4 \\
\hline $26-30$ & 83 & 12.3 & 9.6 & 90.4 \\
\hline $31-35$ & 86 & 12.7 & 15.1 & 84.9 \\
\hline $36-40$ & 66 & 9.7 & 9.1 & 90.9 \\
\hline $41-45$ & 60 & 8.9 & 20.0 & 80.0 \\
\hline $46-50$ & 60 & 8.9 & 8.3 & 91.7 \\
\hline Over 50 & 220 & 32.5 & 9.5 & 90.5 \\
\hline \multicolumn{5}{|c|}{ Residential Self-Selection: Bicycling conditions were a factor in choosing where I live. } \\
\hline Strongly disagree & 191 & 28.2 & 2.6 & 97.4 \\
\hline Disagree & 260 & 38.4 & 5.4 & 94.6 \\
\hline Neither disagree nor agree & 95 & 14.0 & 7.4 & 92.6 \\
\hline Agree & 80 & 11.8 & 35.0 & 65.0 \\
\hline Strongly agree & 51 & 7.5 & 60.8 & 39.2 \\
\hline
\end{tabular}

\subsection{Variables and modelling approach}

\subsubsection{Personal attitudinal factors}

Respondents' attitudes were measured based on their degree of agreement to each attitudinal statement on a Likert Scale of 1 to 5 . The underlying structure of the attitudinal questions was identified using Principal Component Analysis (PCA). PCA, as an efficient statistical tool for addressing multicollinearity among explanatory variables, reduces the number of variables into a smaller set of uncorrelated components (Bro \& Smilde, 2014; Kim, Ko, \& Park, 2015). PCA extraction method was applied with a varimax rotation. This is done to maximize the variance of the squared factor loadings by each component and make the interpretation easier. The squared factor loading is the percent of variance in the respective variable explained by the generated component (Bro \& Smilde, 2014). In our analysis, the 
Kaiser-Meyer-Olkin (KMO) measure of sampling adequacy is 0.722 , indicating the appropriateness of the data used for the PCA. KMO values range from 0 to 1 , and generally values below 0.5 are considered unacceptable for factor analysis. We selected the final set of input variables for the PCA based on the diagonal elements of an anti-image correlation matrix (i.e., KMO statistics for each variable). If the diagonal element was lower than 0.5 , we dropped the respective variable from our analysis. Finally, we only extracted components whose eigenvalues are greater than 1 . With this, twenty-six original variables are summarized into nine attitudinal components.

As shown in Table 2, each component tied closely-associated attitudes, enabling its name to be reasonable and specific. Component 1 (PC1) is named as "conditional willingness to use bicycles," as each statement asks intention to ride a bicycle under a certain condition: more bicycle routes to campus, more covered bicycle parking places on campus, more options for renting bicycles, and for better air quality. Component 2 (PC2) is labeled as "bicycle-friendliness of neighborhoods." It binds the statements asking subjective evaluation of the quality of neighborhoods in terms of bicycling, for instance, bicycle lanes, off-street bicycle trails, traffic along the street, and overall impression. Component 3 (PC3) is named as "sensitivity to safety in mode choice" and it involves the statements on the importance of safety in traffic, safety from crime, and extreme weather conditions. Component 4 (PC4) specifies a list of "perceived obstacles to bicycling on routes" to campus, such as unsafe roadway conditions (e.g., markings, width, signals, and lighting), taking a detour to find suitable lanes for bicyclists, and a lack of bicycle lanes. Component 5 (PC5) particularly addresses "perceived additional benefits of bicycling." For example, reduced environmental impacts, health benefits, and the opportunity to save money are proposed. Component 6 (PC6) contains such statements as "bicyclists do not care about drivers/pedestrians on the street" and is named as "negative attitudes towards bicyclists on the street." Component 7 (PC7) includes two statements related to "availability of bicycle racks," such as "bicycle racks are easy to find," and "there are enough parking racks for bicycles." Component 8 (PC8) is labeled as "concerns about theft," as it asks one's level of agreement towards the statements like "I would not leave my bicycle outside my residence," and "My bicycle might be stolen." Lastly, component 9 (PC9) is named as "familiarity with bicycle-related services," because it deals with the knowledge about bicycle repair shops and proper shower places after bicycling. To test the internal reliability of each factor, we calculated Cronbach's Alpha statistics (Table 2). According to George and Mallery (2003), an alpha value that is lower than 0.5 is unacceptable. Therefore, we dropped PC9, and the resulting eight components are used for subsequent analysis.

Table 2. Principal component analysis (PCA) for bicycling-related attitudinal factors

\begin{tabular}{|c|c|c|c|c|c|c|c|c|c|}
\hline \multirow{2}{*}{ Components } & \multicolumn{9}{|c|}{ Factor Loadings } \\
\hline & 1 & 2 & 3 & 4 & 5 & 6 & 7 & 8 & 9 \\
\hline \multicolumn{10}{|l|}{ PC 1: Conditional Willingness to Use Bicycles } \\
\hline $\begin{array}{l}\text { I would choose to ride a bike if there were more in- } \\
\text { door or covered places to store bikes on campus. }\end{array}$ & $\underline{0.85}$ & 0.05 & 0.04 & 0.00 & 0.07 & 0.02 & -0.12 & 0.13 & -0.06 \\
\hline $\begin{array}{l}\text { I would choose to ride a bike if there were more bike } \\
\text { routes to and from campus. }\end{array}$ & $\underline{0.80}$ & 0.00 & 0.00 & 0.14 & 0.20 & 0.00 & -0.01 & 0.12 & -0.08 \\
\hline $\begin{array}{l}\text { I would choose to ride a bike if there were options for } \\
\text { renting or borrowing bicycles. }\end{array}$ & $\underline{0.80}$ & 0.03 & -0.02 & 0.00 & -0.11 & 0.03 & -0.02 & -0.03 & 0.01 \\
\hline Biking can sometimes be easier for me than driving. & $\underline{0.65}$ & 0.10 & -0.09 & -0.27 & 0.19 & -0.20 & 0.06 & 0.04 & 0.01 \\
\hline I try to ride a bike to help improve air quality. & $\underline{0.60}$ & 0.06 & -0.06 & -0.11 & 0.32 & -0.12 & -0.08 & -0.05 & 0.00 \\
\hline \multicolumn{10}{|l|}{ PC 2: Bicycle-Friendliness of Neighborhoods } \\
\hline Where I now live is a good neighborhood for bicycling. & 0.04 & $\underline{0.85}$ & -0.03 & -0.14 & 0.07 & -0.09 & -0.01 & -0.06 & -0.04 \\
\hline $\begin{array}{l}\text { There are off-street bicycle trails or paved paths in or } \\
\text { near my neighborhood that are easy to access. }\end{array}$ & 0.07 & $\underline{0.81}$ & 0.02 & -0.12 & 0.04 & -0.02 & 0.03 & 0.08 & 0.08 \\
\hline
\end{tabular}




\begin{tabular}{|c|c|c|c|c|c|c|c|c|c|}
\hline There are bike lanes easy to access in my neighborhood. & 0.13 & $\underline{0.78}$ & -0.01 & -0.14 & 0.04 & -0.02 & 0.01 & 0.04 & 0.05 \\
\hline $\begin{array}{l}\text { There is so much traffic along the street I live on that } \\
\text { it would be unpleasant to bicycle in my neighbor- } \\
\text { hood. }\end{array}$ & 0.05 & $\underline{-0.66}$ & 0.12 & 0.10 & -0.04 & 0.16 & 0.03 & 0.14 & 0.08 \\
\hline \multicolumn{10}{|l|}{ PC 3: Sensitivity to Safety in Mode Choice } \\
\hline Safety in traffic is an important factor. & 0.01 & -0.05 & 0.91 & 0.04 & 0.02 & 0.01 & -0.01 & 0.04 & -0.01 \\
\hline Safety from crime is an important factor. & -0.04 & -0.08 & $\underline{0.88}$ & 0.06 & -0.04 & 0.06 & 0.02 & 0.01 & 0.04 \\
\hline Extreme weather conditions are important factors. & -0.05 & -0.01 & $\underline{0.76}$ & 0.01 & 0.00 & -0.03 & -0.02 & 0.06 & -0.06 \\
\hline \multicolumn{10}{|l|}{ PC 4: Perceived Obstacles to Bicycling on Routes } \\
\hline $\begin{array}{l}\text { The roadway conditions on some streets make the } \\
\text { route unsafe for bicyclists on my commute route. }\end{array}$ & -0.05 & -0.17 & 0.07 & $\underline{0.84}$ & 0.07 & 0.04 & -0.03 & 0.05 & -0.04 \\
\hline $\begin{array}{l}\text { I would have to take detours from the most direct } \\
\text { route in order to use bike paths or bike lanes. }\end{array}$ & 0.02 & -0.09 & -0.01 & $\underline{0.83}$ & 0.08 & -0.05 & 0.02 & 0.08 & -0.05 \\
\hline $\begin{array}{l}\text { There are no bicycle lanes or routes near enough for } \\
\text { me to ride. }\end{array}$ & -0.10 & -0.25 & 0.05 & $\underline{0.72}$ & -0.05 & 0.01 & 0.02 & -0.11 & 0.01 \\
\hline \multicolumn{10}{|l|}{ PC 5: Perceived Additional Benefits of Bicycling } \\
\hline Biking reduces environmental impacts. & 0.16 & 0.04 & 0.03 & 0.07 & $\underline{0.89}$ & 0.00 & 0.05 & 0.03 & -0.03 \\
\hline Biking benefits health and fitness. & 0.11 & 0.10 & -0.01 & 0.11 & $\underline{0.88}$ & 0.01 & -0.01 & 0.09 & 0.03 \\
\hline Biking gives me the opportunity to save money. & 0.43 & 0.06 & -0.05 & -0.12 & $\underline{0.52}$ & -0.17 & 0.04 & -0.04 & -0.02 \\
\hline \multicolumn{10}{|c|}{ PC 6: Negative Images towards Bicyclists on the Street } \\
\hline Bicyclists do not care about drivers on the road. & -0.08 & -0.11 & 0.01 & -0.02 & -0.02 & $\underline{0.92}$ & 0.02 & 0.01 & -0.03 \\
\hline Bicyclists do not care about pedestrians on the street. & -0.08 & -0.15 & 0.02 & 0.01 & -0.05 & $\underline{0.91}$ & 0.02 & 0.08 & -0.01 \\
\hline \multicolumn{10}{|l|}{ PC 7: Availability of Bicycle Racks } \\
\hline Bicycle racks are easy to find. & -0.03 & 0.02 & -0.02 & -0.01 & 0.07 & 0.02 & $\underline{0.90}$ & 0.01 & 0.03 \\
\hline There are enough parking racks for bicycles. & -0.10 & -0.01 & 0.01 & 0.02 & -0.02 & 0.02 & $\underline{0.87}$ & -0.11 & 0.14 \\
\hline \multicolumn{10}{|l|}{ PC 8: Concerns about Theft } \\
\hline $\begin{array}{l}\text { I would not leave my bicycle outside my residence } \\
\text { because it might be stolen. }\end{array}$ & 0.07 & -0.10 & -0.02 & -0.05 & 0.08 & -0.06 & -0.03 & $\underline{0.83}$ & 0.04 \\
\hline My bicycle might be stolen even if properly secured. & 0.07 & 0.04 & 0.14 & 0.07 & 0.01 & 0.15 & -0.06 & $\underline{0.74}$ & -0.09 \\
\hline \multicolumn{10}{|l|}{ PC 9: Familiarity with Bicycle-Related Services } \\
\hline I can find a place to help repair my bicycle if needed. & 0.02 & -0.04 & 0.00 & -0.09 & -0.04 & -0.02 & 0.05 & -0.16 & $\underline{0.78}$ \\
\hline $\begin{array}{l}\text { When needed, I can find a convenient place to show- } \\
\text { er and change clothing after bicycling. }\end{array}$ & -0.11 & 0.06 & -0.03 & 0.01 & 0.03 & -0.02 & 0.10 & 0.11 & $\underline{0.78}$ \\
\hline Eigenvalues & 3.10 & 2.62 & 2.25 & 2.12 & 2.07 & 1.82 & 1.62 & 1.40 & 1.28 \\
\hline Cumulative $\%$ of Total Variance & 11.9 & 22.0 & 30.7 & 38.8 & 46.8 & 53.8 & 60.0 & 65.4 & 70.3 \\
\hline Cronbach's Alpha & 0.82 & 0.68 & 0.82 & 0.76 & 0.75 & 0.87 & 0.76 & 0.59 & 0.41 \\
\hline
\end{tabular}

Note: The bold underlined numbers denote that the item is strongly associated with the component.

\subsubsection{Neighborhood clusters}

In this section, we create distinct neighborhood types using k-means cluster analysis. Included in the analysis are the data on the number of intersections of street networks, population, employment, housing density and types, median age of existing housing stock and median household income at the TAZ level. In urbanized areas like the Mid-Ohio area, TAZs are generally smaller than the sizes of census tracts and comparable to census block groups. In the perspective of transportation demand management (TDM), TAZs are the basic unit of analysis in prediction of travel demand, thus the results of a study based on TAZs can be in line with TDM strategies. The respondents were asked to fill in the names of 
two streets intersecting nearest to their residential locations. The coordinates of these intersections are superimposed on the TAZ polygons to match each respondent with a TAZ code. The number of street intersections was counted per each TAZ. Median household income data and median age of the existing housing stock at the census block group level are converted to values at the TAZ level using GIS. The GIS shapefile containing census block group polygons are split into sub-polygons based on the TAZ boundary polygons as split features. The area-weighted average values are calculated based on the values (e.g., median income) of the split census block-group sub-polygons located within each TAZ. The other 4 variables obtained from CTPP are originally available at the TAZ level.

To determine the number of clusters, we take both heuristic and statistical approaches. First, we considered different residential densities (e.g., high, medium, and low densities) and its mix with other activities (e.g., purely residential versus mixed-use). As a result, six neighborhood types were conceived as the initial number of clusters $(\mathrm{k}=6)$. With this, the $324 \mathrm{TAZs}$ that contain 677 respondents are classified into six distinct neighborhood types. However, one cluster covering the TAZs relatively close to campus had only 38 respondents. Thus, we combined this cluster with its closest cluster in terms of land-use and built environment. ANOVA tests for comparison of the centroids of the five clusters turned out to be statistically significant, indicating that the five neighborhood types have significantly different characteristics. To check the statistical quality of the resulting clusters, we computed Silhouette Coefficients for five ( $\mathrm{k}=5)$ and six $(\mathrm{k}=6)$ clusters (Kaufman \& Rousseeuw, 1990). This coefficient ranges from -1 to 1 , with higher values representing stronger structures. The silhouette coefficient for five clusters was 0.451 , higher than that of six clusters (0.412). The five resulting clusters are also consistent with our knowledge on the study area. Therefore, we use these five neighborhood clusters for our analysis.

Table 3 shows the mean values of the land-use and socioeconomic characteristics across the clusters created. Average distance to campus presented in Table 3 indicates the mean commute distance of those who fall into each cluster. The commute distances here are the network-based distances provided by Google Drive API from each respondent's residential location to the center of the campus area. The mean, standard deviation, maximum, and minimum values show that each cluster contains TAZs with various distances of the campus. Figure 1 shows the distribution of these five clusters, which is rather close to a spatially random pattern. Cluster 1 denotes the most populated neighborhoods and Cluster 5 represents the least populated areas among the 324 TAZs. Employment and housing densities roughly follow this trend, indicating that Cluster 1 includes areas with the highest job and housing densities, Cluster 2 has moderate amounts of jobs and higher housing density than Clusters 3, 4, and 5, whereas Cluster 5 consists of the areas with sparse jobs and housing units relative to their area sizes. On the other hand, Clusters 4 and 5 contain the neighborhoods which have much higher median household incomes than others, while Clusters 1 and 2 have relatively lower median household incomes. Taking different qualities of each cluster into account, we named these five clusters as follows:

- Cluster 1: Urban high-density \& Mixed-use neighborhoods

- Cluster 2: Urban medium-density \& Mixed-use neighborhoods

- Cluster 3: Urban medium-density \& Mixed-type residential neighborhoods

- Cluster 4: Urban low-density \& Residential neighborhoods

- Cluster 5: Suburban low-density \& Single-family neighborhoods

In terms of labeling, we make distinction between purely residential neighborhoods versus mixeduse neighborhoods (Kusumastuti \& Nicholson, 2017). Urban Land Institute's Mixed-Use Development Handbook (Schwanke, 2003) defines mixed-use neighborhoods as dense and compact areas that blends residential, commercial, and institutional uses. We label those neighborhoods with higher housing and employment densities and lower percent single-detached houses as mixed-use neighborhoods. Figure 2 illustrates both aerial views and street networks of neighborhoods captured by each cluster. These examples of neighborhood clusters exhibit much difference visually in terms of block size, block 
shape (rectangular, curve, or cul-de-sac), intersection density (the number of intersections per square mile), amount of greenness and land-use diversity. Table 4 shows the usage frequency of each travel mode (days per week) across the clusters. People residing in Clusters 1 and 2 bicycle, walk and take transit more frequently as compared to those living in other clusters.

Table 3. Cluster analysis on land-use and socioeconomic variables

\begin{tabular}{|c|c|c|c|c|c|c|}
\hline Variables & $\begin{array}{c}\text { Cluster } \\
1\end{array}$ & $\begin{array}{c}\text { Cluster } \\
2\end{array}$ & $\begin{array}{c}\text { Cluster } \\
3\end{array}$ & $\begin{array}{c}\text { Cluster } \\
4\end{array}$ & $\begin{array}{c}\text { Cluster } \\
5\end{array}$ & Total \\
\hline $\begin{array}{l}\text { Population Density } \\
\text { (persons/square mile) }\end{array}$ & 9669.4 & 4309.9 & 4276.5 & 3829.9 & 3083.7 & 5223.4 \\
\hline $\begin{array}{l}\text { Employment Density } \\
\text { (persons/square mile) }\end{array}$ & 5039.1 & 2496.2 & 2598.3 & 2264.8 & 1640.8 & 2922.0 \\
\hline $\begin{array}{l}\text { Housing Density } \\
\text { (houses/square mile) }\end{array}$ & 4814.7 & 2288.5 & 1960.7 & 1634.9 & 1121.2 & 2498.7 \\
\hline $\begin{array}{c}\text { Percent } \\
\text { Single-Detached House (\%) }\end{array}$ & 0.24 & 0.47 & 0.63 & 0.76 & 0.91 & 0.56 \\
\hline $\begin{array}{l}\text { Intersection Density } \\
\text { (per square mile) }\end{array}$ & 264.0 & 159.7 & 155.7 & 139.7 & 102.3 & 170.7 \\
\hline $\begin{array}{c}\text { Median } \\
\text { Household Income }\end{array}$ & 20626.2 & 45383.0 & 64421.6 & 85333.2 & 111385.9 & 59634.0 \\
\hline $\begin{array}{c}\text { Median Age } \\
\text { of Existing Housing Stock }\end{array}$ & 53.8 & 44.1 & 41.3 & 40.5 & 34.1 & 43.7 \\
\hline Number of TAZs & 70 & 82 & 76 & 55 & 41 & 324 \\
\hline Number of Observations & 160 & 176 & 158 & 102 & 81 & 677 \\
\hline Average Distance ${ }^{1}$ to Campus (mile) & 4.55 & 6.77 & 8.27 & 8.44 & 8.46 & 6.91 \\
\hline Std. Deviation (mile) & 3.31 & 4.91 & 4.28 & 5.38 & 5.45 & 4.90 \\
\hline Minimum Distance (mile) & 0.72 & 0.86 & 1.06 & 1.23 & 2.07 & 0.72 \\
\hline Maximum Distance (mile) & 17.38 & 19.29 & 20.69 & 21.88 & 21.74 & 21.88 \\
\hline
\end{tabular}

${ }^{1}$ The distance indicates the network-based distance from each respondent's residential location to the geographic center of the university main campus (Thompson Library), provided by Google Drive API. These distances are presented for descriptive purposes; they are not used in creating clusters.

Table 4. Average frequency of travel mode use for commuting across clusters

\begin{tabular}{|c|c|c|c|c|c|c|}
\hline \multirow{2}{*}{ Travel Mode } & \multicolumn{5}{|c|}{ Frequency of Use (days per week, 0: Never, 5: 5 days) } & \multirow{2}{*}{ Total } \\
\cline { 2 - 6 } & Cluster 1 & Cluster 2 & Cluster 3 & Cluster 4 & Cluster 4 & \\
\hline Car $^{*}$ & 2.56 & 3.32 & 3.81 & 3.52 & 4.01 & 3.38 \\
\hline Transit * & 0.29 & 0.79 & 0.23 & 0.21 & 0.16 & 0.38 \\
\hline Bicycle $^{*}$ & 0.72 & 0.34 & 0.31 & 0.34 & 0.19 & 0.40 \\
\hline Walk $^{*}$ & 1.06 & 0.51 & 0.17 & 0.21 & 0.10 & 0.51 \\
\hline Carpool & 0.28 & 0.30 & 0.25 & 0.41 & 0.18 & 0.28 \\
\hline
\end{tabular}

\footnotetext{
* Differences between groups are statistically jointly significant at the $95 \%$ confidence level in one-way ANOVA tests.
} 


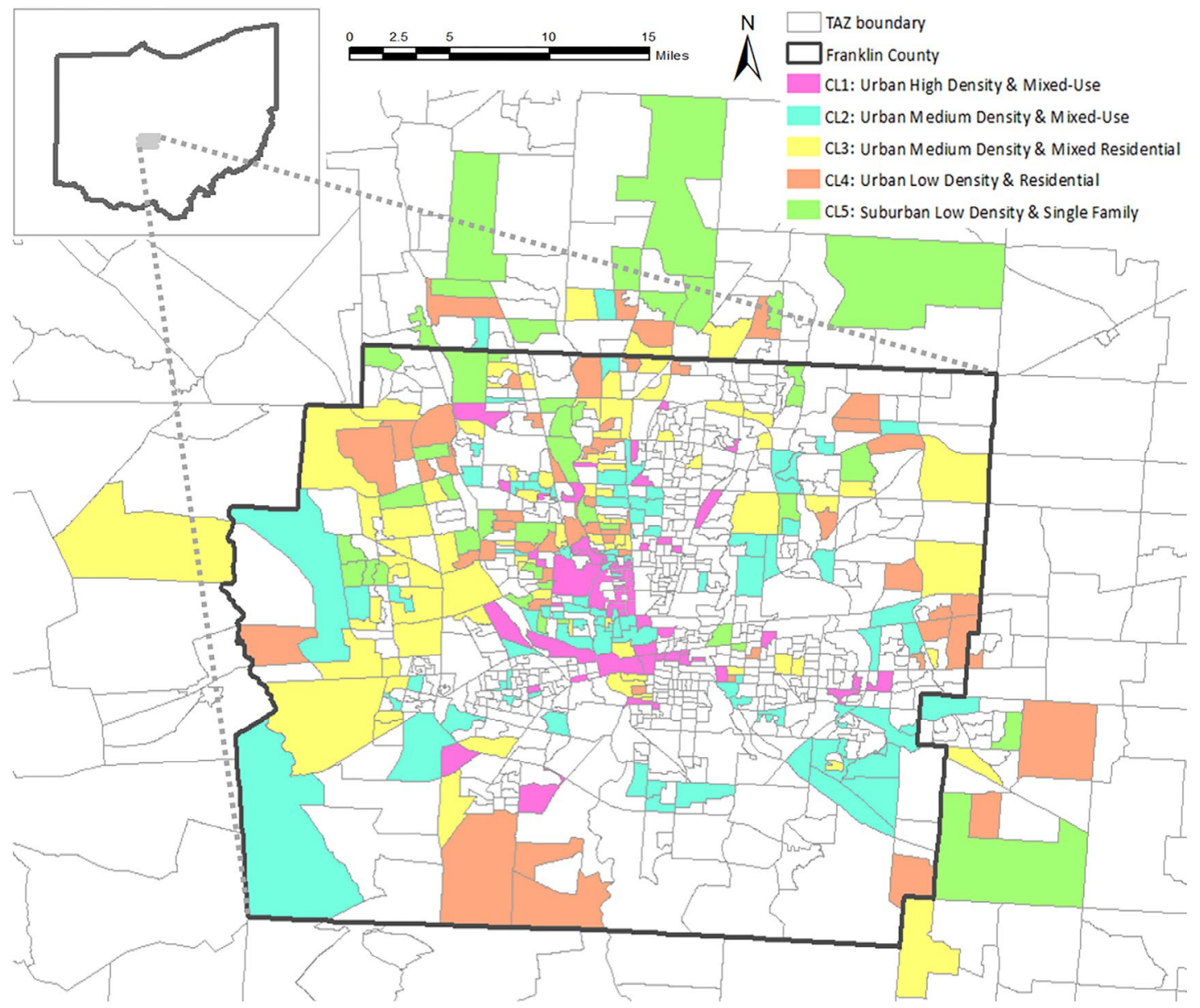

Figure 1. Distribution of TAZ clusters 
Cluster 1:

Urban high-density \& Mixed-use

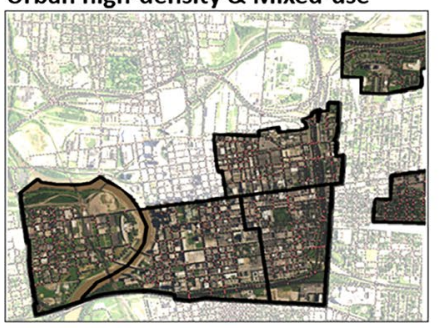

Cluster 4:

Urban low-density \& Residential

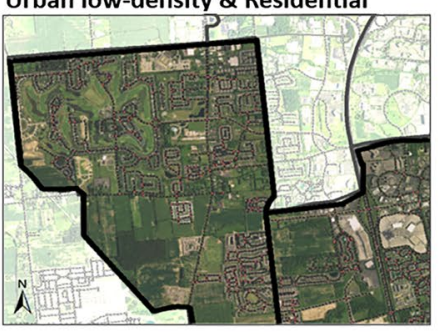

Cluster 1:

Urban high-density \& Mixed-use

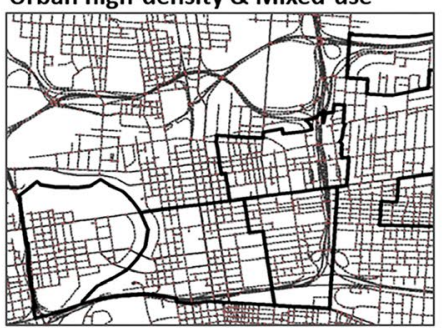

Cluster 4:

Urban low-density \& Residential

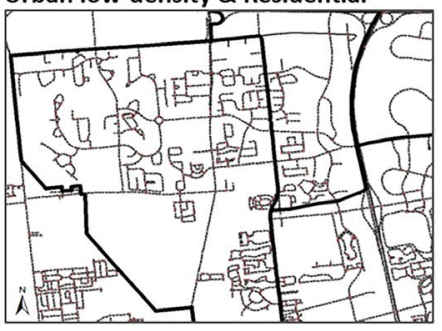

\section{Cluster 2:}

Urban medium-density \& Mixed-use

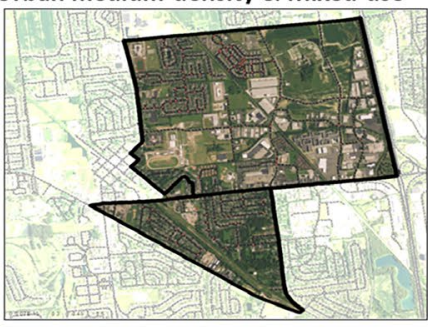

Cluster 5:

Suburban \& Single family

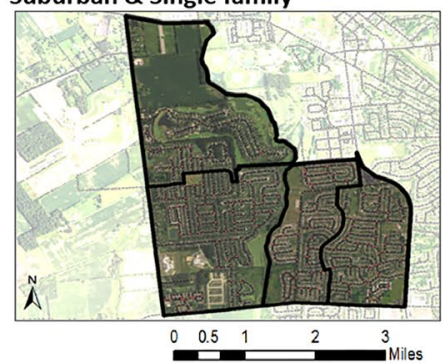

Cluster 2:

Urban medium-density \& Mixed-use

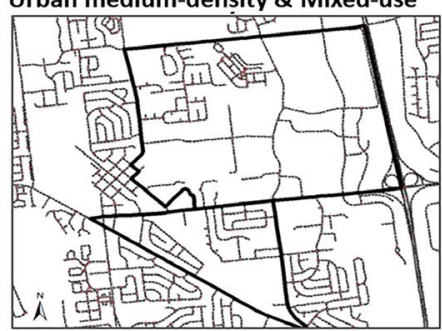

Cluster 5:

Suburban \& Single family

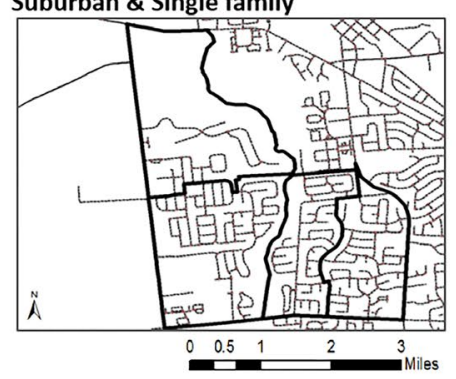

Cluster 3:

Urban medium-density \& Mixed residential

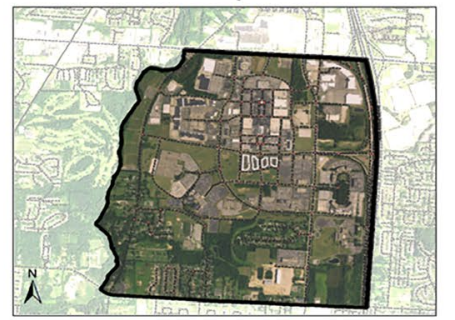

Cluster 3:

Urban medium-density \& Mixed residential

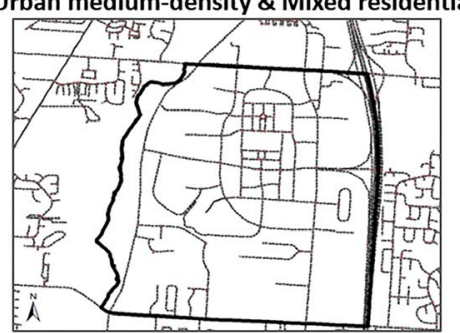

Figure 2. Examples of cluster illustration (traffic analysis zone)

\subsubsection{Binary probit regression analysis}

To analyze the choice of using bicycles for commuting, a binary probit regression is chosen which can handle discrete values as a dependent variable (Kim et al., 2015; McFadden, 1984). The dependent variable in this study is the choice of bicycle commute and has two outcomes:

- 0 , if an individual does not commute by bicycle

- 1 , if the individual commutes by bicycle at least once or more times per week

A binary probit model assumes a continuous unobservable latent variable that underlies the deci- 
sion process of bicycle commuting (LaMondia \& Duthie, 2012; McFadden, 1984). This latent variable can be written as a function of explanatory variables, e.g., sociodemographic, commute distance, attitudinal variables and neighborhood types:

$$
Y^{*}=X^{\prime} \beta+\varepsilon
$$

where $\mathrm{X}$ is a matrix of independent variables, $\beta$ is a vector of coefficients to be estimated with the standard maximum likelihood estimation and $\varepsilon$ is a vector of random error terms that follow standard normal distribution. The continuous latent variable is divided by a breakpoint or threshold $(=0)$ and the probability of the dependent variable, $Y$, taking on a value, 1 , is equal to the probability of the latent variable, $Y^{*}$, taking on values beyond the threshold:

$$
\begin{aligned}
\operatorname{Pr}(Y=1 \mid X) & =\operatorname{Pr}\left(Y^{*}>0\right) \\
& =\operatorname{Pr}\left(X^{\prime} \beta+\varepsilon>0\right) \\
& =\operatorname{Pr}\left(\varepsilon<X^{\prime} \beta\right) \\
& =\Phi\left(X^{\prime} \beta\right)
\end{aligned}
$$

where $\Phi($.$) is in this case the standard normal cumulative distribution function (McFadden, 1984).$

A binary probit regression and a binary logistic regression, a widely used alternative to probit one, differ in the assumption about the distribution of the error term, $\varepsilon$. Logistic models use the standard logistic distribution, whereas probit models assume standard normal distribution of errors, the cumulative distribution function (CDF) of which is known to asymptotically approach to zero slightly more quickly than that of the logistic distribution (McFadden, 1984). Although logistic and probit regression coefficients often vary by a certain magnitude, in this study mostly similar results come out from these two estimation methods. Therefore, we chose a binary probit model that we considered fit our data and model specification better based on goodness-of-fit statistics. To check the validity of estimation results and how stable they are, we apply bootstrapping where we estimate the same model with different subsamples of the same dataset. Specifically, we take random samples from our dataset by selecting $90 \%$ of the data and estimate the same model to account for potential deviation from normal assumption (number of replications $=50$ ).

\section{$4 \quad$ Results and discussion}

\subsection{The association between personal attitudes and neighborhood types}

Tables 5 and 6 show how personal attitudes and perceptions vary between bicyclists and non-bicyclists and among the five neighborhood types. We used Mann-Whitney $U$ test, which is the alternative test to the independent sample t-test. The Mann-Whitney $U$ test is used when the data are ordinal and when it is hard to assume that a variable follows the normal distribution. The test results indicate that bicyclists and non-bicyclists significantly differ in many attitudinal components but PC7 ("availability of bicycle racks") and PC8 ("concerns about theft").

On average, bicyclists most strongly agreed with the statements related to "perceived additional benefits of bicycling" (PC5), including reducing environmental impacts, enjoying health benefits, and saving money. Non-bicyclists also recognized these benefits as being considerable, but not as high as bicyclists did. This means that just a mere recognition of benefits of bicycling may be insufficient to inspire non-bicyclists to start commuting by bicycle. Notably, PC1 ("conditional willingness to use bicycles") seems to be the most discriminating attitudinal factor, followed by PC6 ("negative images towards bicyclists on the street") and PC2 ("bicycle-friendliness of neighborhoods"). Most of the bicyclists agreed that they would ride a bicycle more frequently if bicycle-related facilities are to be improved, such as more bicycle trails, covered bicycle storage places, and bicycle sharing facilities, and also to improve air quality. On the contrary, non-bicyclists' responses demonstrate that they are rather insensitive to facili- 
ties or infrastructure improvement. This implies that improving bicycle facilities may not be as effective in inspiring non-bicyclists as compared to bicyclists. Regarding PC6, non-bicyclists are also different from bicyclists in that they are more likely to perceive bicyclists riding on the street as being careless, whereas bicyclists hardly agree to that negative image.

The average score of PC2 ("bicycle-friendliness of neighborhoods") of bicyclists (=3.61) is higher than that of non-bicyclists (2.97). This significant difference may allow for several interpretations. First of all, it means that many of the bicyclists may live in those neighborhoods with accessible bicycle trails and lanes and relatively less traffic along the street. However, there is a possibility that these bicyclists' perceptions are subjective, varying from one person to another. It is also possible that the bicyclists were much better at finding bicycle-related facilities, because they were bicyclists and more likely to use them than non-bicyclists. This might have led to a more generous rating. Ma \& Dill (2016) suggest that there is a mismatch between objective and perceived built environments. For example, in their study, 36\% of those living in areas with high bikeability reported low bikeability of their neighborhoods, and $46 \%$ of those living in areas with low bikeability had high perceptions of their neighborhoods. Nevertheless, they found that both actual and perceived built environments are significantly associated with utilitarian bicycling, while only perceived environments are significant in recreational bicycling. Thus, it can be stated that, whether subjective or objective, bicyclists are more likely to live in neighborhoods which they evaluate as of good quality for bicycling. Secondly, as for causality, it is uncertain whether these bicycle-friendly neighborhoods affected their bicycle choices in the first place, or they chose them to move in there because of their better bicycle environments. This relates to the issue of residential self-selection. As can be seen in Table 5, bicyclists' mean score of the degree of residential self-selection is 3.78, much higher than that of non-bicyclists (2.11). Therefore, bicyclists' more positive recognition of their neighborhoods may have grounds, at least partly, as they consciously choose their residential locations based on bikeability. This relationship should be explicitly taken into account in empirical modelling.

Regarding deterrents, non-bicyclists reported higher levels of agreement to the statements included in PC3 ("sensitivity to safety in mode choice") and PC4 ("perceived obstacles to bicycling on routes"). These two components, including safety from crime and traffic, threatening roadway conditions, and taking detours to bicycle, represent significant deterrents to bicycling commute. For PC4, even bicyclists' mean score lies slightly above the neutral degree (3.31). Non-bicyclists are sensitive to safety and weather issues more than bicyclists, but bicyclists think of these conditions as an important factor as well, and the gap between two groups is not as critical as in other significant components. The differences between bicyclists and non-bicyclists are not obvious in PC7 ("availability of bicycle racks") and PC8 ("concerns about theft"). Both groups have comparatively high levels of concerns about bicycle theft (3.68 vs. 3.59).

Table 5. Comparison of personal attitudes and residential self-selection

\begin{tabular}{|l|c|c|c|c|}
\hline \multirow{2}{*}{ Means of Attitudes for Each Group* } & \multicolumn{2}{|c|}{$\begin{array}{c}\text { Bicyclists } \\
(N=85)\end{array}$} & \multicolumn{2}{c|}{$\begin{array}{c}\text { Non-Bicyclists } \\
(N=592)\end{array}$} \\
\cline { 2 - 5 } & Mean & SD & Mean & SD \\
\hline PC1: Conditional Willingness to Use Bicycles & $\mathbf{3 . 8 0}$ & $\mathbf{1 . 2 0}$ & $\mathbf{2 . 7 0}$ & $\mathbf{1 . 1 8}$ \\
\hline PC2: Bicycle-Friendliness of Neighborhoods & $\mathbf{3 . 6 1}$ & $\mathbf{1 . 1 9}$ & $\mathbf{2 . 9 7}$ & $\mathbf{1 . 2 7}$ \\
\hline PC3: Sensitivity to Safety in Mode Choice & $\mathbf{3 . 3 8}$ & $\mathbf{1 . 1 9}$ & $\mathbf{3 . 8 8}$ & $\mathbf{1 . 1 5}$ \\
\hline PC4: Perceived Obstacles to Bicycling on Routes & $\mathbf{3 . 3 1}$ & $\mathbf{1 . 3 7}$ & $\mathbf{3 . 8 1}$ & $\mathbf{1 . 1 0}$ \\
\hline PC5: Perceived Additional Benefits of Bicycling & $\mathbf{4 . 6 7}$ & $\mathbf{0 . 5 6}$ & $\mathbf{4 . 0 6}$ & $\mathbf{0 . 9 6}$ \\
\hline PC6: Negative Images towards Bicyclists on the Street & $\mathbf{2 . 6 6}$ & $\mathbf{1 . 0 6}$ & $\mathbf{3 . 3 1}$ & $\mathbf{1 . 0 9}$ \\
\hline PC7: Availability of Bicycle Racks & 2.95 & 1.21 & 3.09 & 0.85 \\
\hline PC8: Concerns about Theft & 3.68 & 1.11 & 3.59 & 1.10 \\
\hline The Degree of Residential Self-Selection & $\mathbf{3 . 7 8}$ & $\mathbf{1 . 2 7}$ & $\mathbf{2 . 1 1}$ & $\mathbf{1 . 0 5}$ \\
\hline
\end{tabular}

* Group means in bold indicate that differences between groups are statistically significant at the $95 \%$ (p-value $<0.05$ ) level using MannWhitney U Test 
We also examine whether commuters living in different types of neighborhoods have different attitudes. Table 6 shows two results of the Kruskall-Wallis test, a k-group version of Mann-Whitney U test for ordinal variables: a) mean scores of respondents living in each cluster (i.e., each neighborhood type) for each attitudinal component, and b) those attitudinal components that are statistically different across clusters at the $90 \%$ and $95 \%$ levels. The results show that the degree of "conditional willingness to use bicycles" (PC1) decreases gradually from Cluster 1 to Cluster 5. This indicates that people living in higher density neighborhoods are more likely to use bicycles than people living in lower-density neighborhoods if facilities are improved.

As to perceived bikeability, people living in medium-density mixed-use neighborhoods (Cluster 2) reveal the least positive perceptions towards the bikeability of their neighborhoods (PC2, "bicyclefriendliness of neighborhoods"), followed by people living in high-density mixed-use neighborhoods (Cluster 1). People living in suburban single-family neighborhoods (Cluster 5) are the ones who bear the most positive feelings about the bicycle-friendliness of their neighborhoods (3.36). This favorable attitude may be related to lower volumes of traffic and the presence of bicycle trails and bicycle lanes in the neighborhoods grouped under Cluster 5 . However, it is possible that people living in these neighborhoods are only using these trails and lanes for recreational purposes. Generally, high-density mixed-use neighborhoods (Cluster1) and urban medium-density mixed-use neighborhoods (Cluster 2) tend to have higher volumes of traffic as compared to lower-density residential neighborhoods. Relatedly, people living in medium-density neighborhoods (Clusters 2 and 3) are more sensitive to safety in mode choice (PC3) (e.g., safety from crime and traffic, and extreme weather conditions) than others. People living in higher density mixed-use neighborhoods (Clusters 1 and 2) have relatively higher concerns about bicycle theft (PC8).

If we compare PC2 with PC4 ("perceived obstacles to bicycling on routes"), medium-density mixed-type residential neighborhoods (Cluster 3) and people living in suburban single-family neighborhoods (Cluster 5) report the highest inconvenience, whereas people in Cluster 4 (low-density residential neighborhoods) recognize the fewest obstacles on their commute routes. This is a bit surprising because those first two clusters (Clusters 3 and 5) have relatively higher mean scores of PC2 ("bicycle-friendliness of neighborhoods"). This contrasting result means that we need to treat the bikeability of neighborhoods and the bikeability of travel routes to workplace separately, especially in a bicycle commute choice context.

We have found no significant differences among neighborhood types with respect to perceived additional benefits of bicycling (PC5), negative images towards bicyclists on the street (PC6), and knowledge on the availability of bicycle racks (PC7). Interestingly, there is little difference in the self-reported degree of residential self-selection among different neighborhood types (Table 6). 
Table 6. Comparison of attitudes and residential self-selection between clusters

\begin{tabular}{|c|c|c|c|c|c|}
\hline \multirow{3}{*}{ Means of Personal Attitudes for Each Cluster * } & Cluster 1 & Cluster 2 & Cluster 3 & Cluster 4 & Cluster 5 \\
\hline & $(N=160)$ & $(N=176)$ & $(N=158)$ & $(N=102)$ & $(N=81)$ \\
\hline & Mean (SD) & Mean (SD) & Mean (SD) & Mean $(\mathrm{SD})$ & Mean (SD) \\
\hline PC1: Conditional Willingness to Use Bicycles & $\begin{array}{c}3.02 \\
(1.31)\end{array}$ & $\begin{array}{c}2.90 \\
(1.19)\end{array}$ & $\begin{array}{c}2.83 \\
(1.21)\end{array}$ & $\begin{array}{c}2.63 \\
(1.22)\end{array}$ & $\begin{array}{c}2.65 \\
(1.23)\end{array}$ \\
\hline PC2: Bicycle-Friendliness of Neighborhoods & $\begin{array}{c}2.95 \\
(1.32)\end{array}$ & $\begin{array}{c}2.88 \\
(1.22)\end{array}$ & $\begin{array}{c}3.09 \\
(1.26)\end{array}$ & $\begin{array}{c}3.19 \\
(1.28)\end{array}$ & $\begin{array}{c}3.36 \\
(1.29)\end{array}$ \\
\hline PC3: Sensitivity to Safety in Mode Choice & $\begin{array}{c}3.75 \\
(1.25)\end{array}$ & $\begin{array}{c}3.84 \\
(1.11)\end{array}$ & $\begin{array}{c}3.98 \\
(1.09)\end{array}$ & $\begin{array}{l}3.67 \\
(1.2)\end{array}$ & $\begin{array}{c}3.72 \\
(1.16)\end{array}$ \\
\hline PC4: Perceived Obstacles to Bicycling on Routes & $\begin{array}{c}3.73 \\
(1.15)\end{array}$ & $\begin{array}{c}3.72 \\
(1.12)\end{array}$ & $\begin{array}{c}3.87 \\
(1.09)\end{array}$ & $\begin{array}{c}3.53 \\
(1.27)\end{array}$ & $\begin{array}{c}3.82 \\
(1.15)\end{array}$ \\
\hline PC5: Perceived Additional Benefits of Bicycling & $\begin{array}{c}4.19 \\
(0.93)\end{array}$ & $\begin{array}{l}4.15 \\
(0.86)\end{array}$ & $\begin{array}{c}4.13 \\
(0.92)\end{array}$ & $\begin{array}{c}4.07 \\
(1.01)\end{array}$ & $\begin{array}{c}4.12 \\
(1.06)\end{array}$ \\
\hline $\begin{array}{l}\text { PC6: Negative Attitudes towards Bicyclists on the } \\
\text { Street }\end{array}$ & $\begin{array}{c}3.30 \\
(1.17) \\
\end{array}$ & $\begin{array}{c}3.26 \\
(1.05) \\
\end{array}$ & $\begin{array}{c}3.27 \\
(1.07) \\
\end{array}$ & $\begin{array}{c}3.10 \\
(1.16) \\
\end{array}$ & $\begin{array}{c}3.11 \\
(1.09) \\
\end{array}$ \\
\hline PC7: Availability of Bicycle Racks & $\begin{array}{l}3.13 \\
(0.93)\end{array}$ & $\begin{array}{l}3.08 \\
(0.86)\end{array}$ & $\begin{array}{c}3.01 \\
(0.84)\end{array}$ & $\begin{array}{c}3.12 \\
(0.97)\end{array}$ & $\begin{array}{c}3.02 \\
(0.97)\end{array}$ \\
\hline PC8: Concerns about Theft & $\begin{array}{c}3.82 \\
(1.05)\end{array}$ & $\begin{array}{c}3.66 \\
(1.06)\end{array}$ & $\begin{array}{c}3.57 \\
(1.08)\end{array}$ & $\begin{array}{c}3.36 \\
(1.14)\end{array}$ & $\begin{array}{c}3.43 \\
(1.21)\end{array}$ \\
\hline The Degree of Residential Self-Selection & $\begin{array}{c}2.46 \\
(1.35)\end{array}$ & $\begin{array}{l}2.25 \\
(1.1)\end{array}$ & $\begin{array}{c}2.23 \\
(1.16)\end{array}$ & $\begin{array}{c}2.46 \\
(1.28)\end{array}$ & $\begin{array}{c}2.2 \\
(1.17)\end{array}$ \\
\hline Differences in Attitudes between Clusters ** & Cluster1 & Cluster2 & Cluster3 & Cluster4 & Cluster5 \\
\hline Cluster1: Urban High-Density \& Mixed-Use & & - & $\begin{array}{l}\text { PC1, } \\
\text { PC2, } \\
\text { PC3, } \\
\text { PC8 }\end{array}$ & $\begin{array}{l}\text { PC1, } \\
\text { PC2, } \\
\text { PC8 }\end{array}$ & $\begin{array}{l}\text { PC1, } \\
\text { PC2, } \\
\text { PC8 }\end{array}$ \\
\hline Cluster 2: Urban Medium-Density \& Mixed-Use & & & PC2 & $\begin{array}{l}\text { PC1, } \\
\text { PC2, } \\
\text { PC8 }\end{array}$ & $\begin{array}{l}\text { PC1, } \\
\text { PC2, }\end{array}$ \\
\hline $\begin{array}{l}\text { Cluster 3: Urban Medium-Density \& Mixed Resi- } \\
\text { dential }\end{array}$ & & & & $\begin{array}{l}\text { PC1, } \\
\text { PC3, } \\
\text { PC4 }\end{array}$ & $\begin{array}{l}\text { PC2, } \\
\text { PC3 }\end{array}$ \\
\hline Cluster 4: Urban Low-Density \& Residential & & & & & PC4 \\
\hline $\begin{array}{l}\text { Cluster 5: Suburban \& Single-Family Neighbor- } \\
\text { hoods }\end{array}$ & & & & & \\
\hline
\end{tabular}

* Group means in bold indicate differences between groups are statistically jointly significant at the $95 \%$ (p-value $<0.05$ ) level using Kruskall-Wallis Test

** The results of ANOVA post-hoc multiple comparisons with bold text indicate $95 \%$ (p-value $<0.05)$ confidence level and with regular text $90 \%$ (p-value $<0.1$ )

\subsection{Binary probit estimation results}

Binary probit models with four different specifications are estimated with bootstrapping applied to assess the probabilities of riding a bicycle for commuting at least once a week. As shown in Table 7, Model 4, which includes all attitudinal and neighborhood variables along with the residential self-selection variable, has the highest explanatory power. It predicts correctly $92.5 \%$ of the observed choices of being bicyclists and non-bicyclists. Controlling all possible facets of influence is important to measure the distinctive effect of each variable.

For sociodemographic variables, gender and university affiliation variables are found to be significant. If a traveler is female, the probability of being a bicyclist decreases. Being a graduate student and 
undergraduate student increases the likelihood of commuting by bicycle as compared to staff members. Being a faculty member has no difference. The commute distance of 5 to 10 miles from campus becomes not significant after attitudinal components are considered. This implies that part of the variance originally accounted for by being at a 5 to 10 mile commute distance is now better explained by commuters' personal attitudes. This finding is in line with that of Heinen et al. (2011) that commuting long distances $(>5 \mathrm{~km})$ by bicycle is more strongly influenced by attitudes than shorter distances.

In Models 1, 3 and 4, certain neighborhood types are identified to be negatively associated with bicycling choices. The results show that medium-density mixed-use neighborhoods (Cluster 2) and suburban low-density, single-family residential neighborhoods (Cluster 5) are likely to discourage bicycle commuting as compared to high-density mixed-use neighborhoods (Cluster 1). Although the relative sizes of their coefficients to the constant term get slightly smaller as attitudinal and self-selection variables are included, it is consistent that living in medium-density mixed-use neighborhoods and in suburban traditional neighborhoods are negatively associated with commuters' bicycling choices. The possible reasons behind these negative associations seem to vary. Cluster 2 represents neighborhoods with higher housing densities and lower income levels as compared to Clusters 3, 4, and 5, but with much lower street connectivity as compared to Cluster 1 . These factors might have promoted other commute modes rather than bicycling, such as transit. For example, data presented in Table 4 indicates that people in Cluster 2 tend to use transit more frequently ( 0.79 days per week on average) than those in other Clusters (ranging from 0.16 to 0.29 days per week on average). Cluster 5 represents predominantly singlefamily residential areas with high income levels, low housing densities, and poor street connectivity. These attributes might have undermined the attractiveness of bicycle commute for residents.

The variable indicating the self-reported degree of residential self-selection in Model 4 possesses significant effects on bicycling. The more strongly one agrees to their residential location choice in favor of bicycling, the more plausible a commuter decides to use bicycles for commute. Notably, Cluster 4, representing urban low-density residential neighborhoods, was not significant in Models 1 and 3, but becomes significant at the $10 \%$ significance level in Model 4 which accounts for the residential selfselection effect. This change may imply that the residential self-selection effect, which means residential choice for bicycle travel, partly explains why some people in this type of neighborhoods ride to commute. If we filter this effect out, living in a low-density residential neighborhood may have a negative impact on bicycling choice. In any model, Cluster 3 (medium-density residential neighborhoods) is not statistically significant with respect to bicycle choice, even though Cluster 3 shares some similar properties with Clusters 2 and 4 in terms of population density, employment and intersection densities. This result indicates that individual land-use density variables may not perform well if used individually, due to potential non-linearities.

The estimation results of Models 3 and 4 also demonstrate substantive effects of the attitudinal components on bicycle commuting choice, except for PC7 and PC8. Conditional willingness to use bicycles (PC1) and perceived additional benefits of bicycling (PC5) are most likely to stimulate commuters to use bicycles. On the contrary, negative images towards bicyclists on the street (PC6), sensitivity to safety in mode choice (PC3), and perceived obstacles to bicycling on routes (PC4) are negative factors that would inhibit bicycle commuting. Bicycle-friendliness of neighborhoods (PC2) is a positive predictor of bicycle choice, though the size of impact is relatively weak. Attitudes associated with availability of bicycle racks (PC7) and concerns about theft (PC8) are not significant. This means that the factors, such as having enough parking racks and concerns about bicycle theft, have little to do with the choice of bicycle commute. We find that "conditional willingness to use bicycles" has the largest impact, followed by "perceived additional benefits of bicycling" and "negative images towards bicyclists on the street." Specifically, such attitudes as environmental awareness, needs for exercise, sensitivity to facilities 
improvement, and positive social images of bicyclists may exert considerable influences on bicycle commuting behavior.

\subsection{Discussions and study limitations}

Our findings suggest significant associations among personal attitudes, perceptions, neighborhood types and bicycling behaviors. The findings indicate that different perspectives and behaviors of individuals regarding bicycling are associated with neighborhoods types that they reside in. We also find that bicyclists are likely to choose residential locations based on their bicycling preferences than non-bicyclists, although the differences in the degree of self-selection are not statistically significant across neighborhood types. Positive attitudes, strong agreement to benefits of bicycling, and perceived images of bicyclists have sizeable effects on bicycle use for commuting. Overall, results imply that policy-makers may be able to better utilize the associations among people's attitudes, perceptions, and their neighborhood environments. For example, planners can formulate policies or targeted investments in facilities that are intended to improve the perception of public safety from crime and traffic along the street by installing street lights, stepping up security, and providing separate bicycle lanes. That is, efforts to enhance the public awareness on benefits of bicycling need to be accompanied by changes in associated builtenvironment characteristics and neighborhood bicycle infrastructure.

As any other research endeavor, this research faced some limitations. For instance, this study did not consider the frequency of bicycling. This is because the sample did not include a large number of bicyclists, thus further disaggregating the sample into smaller sub-groups was not desirable. The effects of attitudes, urban form and socioeconomics may vary across individuals with different bicycling frequency levels. This study is based on a university commuter sample at a single year and thus the results may not easily be generalized into urban settings with various destinations with different characteristics. However, the methodology and the results of this study can be used and extended to provide insights for future research on bicycle commuting in other settings. Lastly, in this study we considered the characteristics of residential neighborhoods, which are the origins of university commuters, but we did not consider the characteristics of their chosen routes to campus which may be of relevance, as we did not have data on these. 
Table 7. Binary probit model estimation results

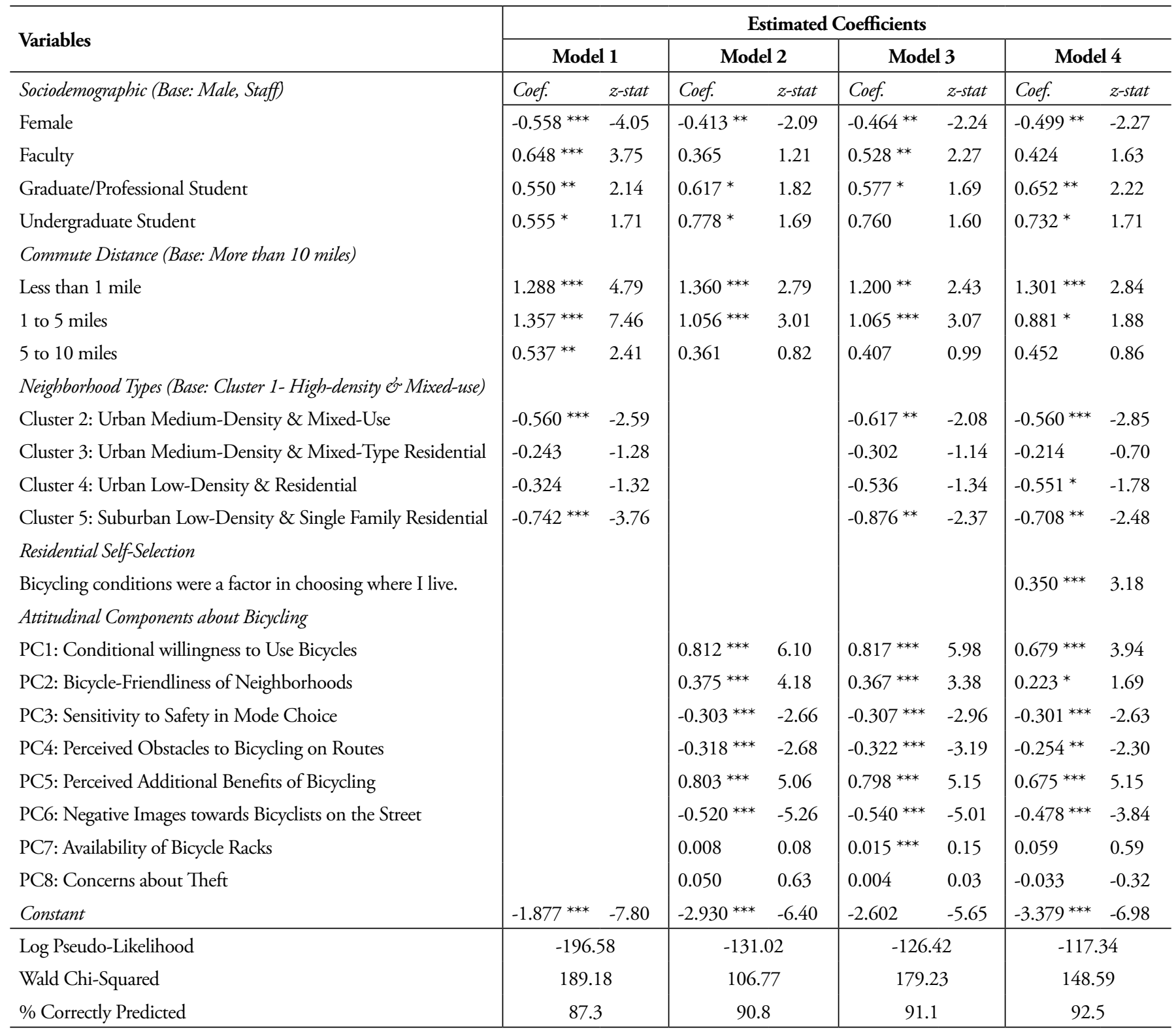

Note $^{* * *}$ : significant at the $99 \%$ confidence level, ${ }^{* *}$ significant at the $95 \%$ confidence level, * significant at the $90 \%$ confidence level

\section{$5 \quad$ Conclusions}

Despite versatile roles and benefits of bicycle commuting, still a very limited number of people use bicycles for their daily commute in the U.S. This study aimed at examining the bicycle commuting choice of university commuters, focusing on the diverse aspects of this decision using variables representing: (i) a commuter's personal attitudes towards bicycling and evaluations of bicycle-specific facilities and environmental elements, (ii) a typology of residential neighborhood characteristics, such as land-use and socioeconomic properties, and (iii) residential self-selection. Relying on the data from the 2015 Campus Travel Pattern Survey of The Ohio State University, this study found that the decision to commute by bicycle involved diverse factors reflecting individuals' attitudes, preference, and residential neighborhood types. 
The results showed that certain neighborhood types, i.e., medium-density mixed-use neighborhoods, low-density upper-income residential neighborhoods, suburban single-family neighborhoods, were negatively associated with bicycling commute choice as compared to high-density mixed-use neighborhoods. Although the cross-sectional data used in this study do not allow for fully controlling for residential self-selection, accounting for the self-reported degree of residential self-selection and diverse attitudinal components helped control for some of these effects. The results also revealed that residential self-selection and positive attitudes towards bicycling may better explain bicycle commute choice of individuals living in low-density residential neighborhoods.

This study also explored the relationships between personal attitudes and neighborhood types. The conditional willingness to bicycle, deterrents to riding a bicycle to campus, sensitivity to safety, and perceived bicycle-friendliness of neighborhoods differed significantly across residential neighborhood types. Those who live in higher-density mixed-use neighborhoods were more likely to be willing to use a bicycle if bicycle facilities were to be improved. Residents in lower-density affluent neighborhoods (Clusters 4 and 5) were likely to report higher scores of bicycle-friendliness of their own neighborhoods, but at the same time they tended to report high scores of perceived obstacles on the way to campus, suggesting that the bikeability of neighborhoods and the bikeability of travel routes should be treated different. The significant attitudinal differences between people living in different neighborhoods may imply that people residing in similar neighborhood types are likely to have similar attitudes and travel outcomes. It is also likely that people with similar attitudes prefer similar neighborhood types, as is often the case from the residential self-selection perspective. These relationships may need further exploration in future research.

\section{Acknowledgements}

This research was partially funded by NEXTRANS USDOT Region V Regional University Transportation Center. The authors would like to thank Mi Namgung, Dale Harris and Rob Osterfeld for their efforts in survey design and dissemination. Thanks also go to all survey respondents who took the time to provide valuable information.

\section{Data availability}

The raw data of the survey can be obtained per request to the corresponding author or to the Facilities Operations and Development at The Ohio State University (senior manager: Robert Osterfeld, osterfeld.5@osu.edu). In addition to the survey data, the other datasets used in the paper are all public. Neighborhood socioeconomic characteristics, land-use and street infrastructure data were obtained from the US Census Bureau TIGER system, American Community Survey (ACS), and Census Transportation Planning Product (CTPP) at the TAZ (Traffic Analysis Zone) and census block group level. 


\section{References}

Akar, G., Chen, N., \& Gordon, S. I. (2016). Influence of neighborhood types on trip distances: Spatial error models for Central Ohio. International Journal of Sustainable Transportation, 10(3), 284-293.

Akar, G., Flynn, C., \& Namgung, M. (2012). Travel choices and links to transportation demand management: Case study at Ohio State University. Transportation Research Record: Journal of the Transportation Research Board, 2319, 77-85.

Akar, G., Fischer, N., \& Namgung, M. (2013). Bicycling choice and gender case study: The Ohio State University. International Journal of Sustainable Transportation, 7(5), 347-365.

Bro, R., \& Smilde, A. K. (2014). Principal component analysis. Analytical Methods, 6(9), 2812-2831.

Bopp, M., Kaczynski, A., \& Wittman, P. (2011). Active commuting patterns at a large, Midwestern college campus. Journal of American College Health, 59(7), 605-611.

Buehler, R., \& Pucher, J. (2012). Cycling to work in 90 large American cities: New evidence on the role of bike paths and lanes. Transportation, 39(2), 409-432.

Cao, X., Mokhtarian, P. L., \& Handy, S. L. (2009). Examining the impacts of residential self-selection on travel behavior: A focus on empirical findings. Transport Reviews, 29(3), 359-395.

Cervero, R., \& Kockelman, K. (1997). Travel demand and the 3Ds: Density, diversity, and design. Transportation Research Part D: Transport and Environment, 2(3), 199-219.

Chatterjee, K., Sherwin, H., \& Jain, J. (2013). Triggers for changes in cycling: The role of life events and modifications to the external environment. Journal of Transport Geography, 30, 183-193.

Cole-Hunter, T., Donaire-Gonzalez, D., Curto, A., Ambros, A., Valentin, A., Garcia-Aymerich, J., ... Nieuwenhuijsen, M. (2015). Objective correlates and determinants of bicycle commuting propensity in an urban environment. Transportation Research Part D: Transport and Environment, 40, 132-143.

Daley, M., \& Rissel, C. (2011). Perspectives and images of cycling as a barrier or facilitator of cycling. Transport Policy, 18(1), 211-216.

Damant-Sirois, G., \& El-Geneidy, A. M. (2015). Who cycles more? Determining cycling frequency through a segmentation approach in Montreal, Canada. Transportation Research Part A: Policy and Practice, 77, 113-125.

Dill, J., Mohr, C., \& Ma, L. (2014). How can psychological theory help cities increase walking and bicycling? Journal of the American Planning Association, 80(1), 36-51.

Dill, J., \& Voros, K. (2007). Factors affecting bicycling demand: Initial survey findings from the Portland, Oregon, region. Transportation Research Record: Journal of the Transportation Research Board, 2031, 9-17.

DuMouchel, W. H., \& Duncan, G. J. (1983). Using sample survey weights in multiple regression analyses of stratified samples. Journal of the American Statistical Association, 78(383), 535-543.

Ettema, D., \& Nieuwenhuis, R. (2017). Residential self-selection and travel behavior: What are the effects of attitudes, reasons for location choice and the built environment? Journal of Transport Geography, 59, 146-155.

Ewing, R., \& Cervero, R. (2010). Travel and the built environment. Journal of the American Planning Association, 76(3), 265-294.

Fernández-Heredia, Á., Monzón, A., \& Jara-Díaz, S. (2014). Understanding cyclists’ perceptions, keys for a successful bicycle promotion. Transportation Research Part A: Policy and Practice, 63, 1-11.

Gatersleben, B., \& Appleton, K. M. (2007). Contemplating cycling to work: Attitudes and perceptions in different stages of change. Transportation Research Part A: Policy and Practice, 41(4), 302-312.

George, D., \& Mallery, P. (2003). SPSS for windows step by step: A simple guide and reference, 4th edition. Boston: Allyn \& Bacon. 
Handy, S., Cao, X., \& Mokhtarian, P. L. (2006). Self-selection in the relationship between the built environment and walking: Empirical evidence from Northern California. Journal of the American Planning Association, 72(1), 55-74.

Harding, C., Patterson, Z., Miranda-Moreno, L. F., \& Zahabi, S. A. H. (2012). Modeling the effect of land use on activity spaces. Transportation Research Record, 2323(1), 67-74.

Heinen, E., Maat, K., \& Van Wee, B. (2011). The role of attitudes toward characteristics of bicycle commuting on the choice to cycle to work over various distances. Transportation Research Part D: Transport and Environment, 16(2), 102-109.

Kaufman, L., \& Rousseeuw, P. J. (1990). Partitioning around medoids. Finding groups in data: An introduction to cluster analysis (pp.68-125). Hoboken, NJ: John Wiley and Sons.

Kim, D., Ko, J., \& Park, Y. (2015). Factors affecting electric vehicle sharing program participants' attitudes about car ownership and program participation. Transportation Research Part D: Transport and Environment, 36, 96-106.

Kusumastuti, D., \& Nicholson, A. (2017). Mixed-use development in Christchurch, New Zealand: Do you want to live there? Urban Studies, 55(12), 2682-2702

LaMondia, J., \& Duthie, J. (2012). Analysis of factors influencing bicycle-vehicle interactions on urban roadways by ordered probit regression. Transportation Research Record: Journal of the Transportation Research Board, 2314, 81-88.

Li, Z., Wang, W., Yang, C., \& Ragland, D. R. (2013). Bicycle commuting market analysis using attitudinal market segmentation approach. Transportation Research Part A: Policy and Practice, 47, 5668.

Ma, L., \& Dill, J. (2015). Associations between the objective and perceived built environment and bicycling for transportation. Journal of Transport \& Health, 2(2), 248-255.

Ma. L., \& Dill. J. (2016). Do people's perceptions of neighborhood bikeability match "reality"? Journal of Transport and Land-Use, 10(1), 291-308.

Maldonado-Hinarejos, R., Sivakumar, A., \& Polak, J. W. (2014). Exploring the role of individual attitudes and perceptions in predicting the demand for cycling: A hybrid choice modelling approach. Transportation, 41(6), 1287-1304.

Manaugh, K., Miranda-Moreno, L. F., \& El-Geneidy, A. M. (2010). The effect of neighborhood characteristics, accessibility, home-work location, and demographics on commuting distances. Transportation, 37(4), 627-646.

Marshall, W., \& Garrick, N. (2010) Effect of street network design on walking and biking. Transportation Research Record: Journal of the Transportation Research Board, 2198, 103-115.

McFadden, D. L. (1984). Econometric analysis of qualitative response models. Handbook of Econometrics, 2, 1395-1457.

Motoaki, Y., \& Daziano, R. A. (2015). A hybrid-choice latent-class model for the analysis of the effects of weather on cycling demand. Transportation Research Part A: Policy and Practice, 75, 217-230.

Muñoz, B., Monzon, A., \& López, E. (2016). Transition to a cyclable city: Latent variables affecting bicycle commuting. Transportation Research Part A: Policy and Practice, 84, 4-17.

Oakil, A. T. M., Ettema, D., Arentze, T., \& Timmermans, H. (2016). Bicycle commuting in the Netherlands: An analysis of modal shift and its dependence on life cycle and mobility events. International Journal of Sustainable Transportation, 10(4), 376-384.

Oliva, I., Galilea, P., \& Hurtubia, R. (2018). Identifying cycling-inducing neighborhoods: A latent class approach. International Journal of Sustainable Transportation, 12(10), 701-713.

Piatkowski, D. P., \& Marshall, W. E. (2015). Not all prospective bicyclists are created equal: The role of attitudes, socio-demographics, and the built environment in bicycle commuting. Travel Behavior and Society, 2(3), 166-173.

Pinjari, A., Eluru, N., Bhat, C., Pendyala, R., \& Spissu, E. (2008). Joint model of choice of residential 
neighborhood and bicycle ownership: Accounting for self-selection and unobserved heterogeneity. Transportation Research Record: Journal of the Transportation Research Board, 2082, 17-26.

Porter, A. K., Salvo, D., Perez, A., Reininger, B., \& Kohl, H. W. (2018). Intrapersonal and environmental correlates of bicycling in US adults. American Journal of Preventive Medicine, 54(3), 413-418.

Rodriguez, D. A., \& Joo, J. (2004). The relationship between non-motorized mode choice and the local physical environment. Transportation Research Part D: Transport and Environment, 9(2), 151-173.

Schoner, J. E., Cao, J., \& Levinson, D. M. (2015). Catalysts and magnets: Built environment and bicycle commuting. Journal of Transport Geography, 47, 100-108.

Schwanke, D. (2003). Mixed-use development handbook. Washington, DC: Urban Land Institute.

Sisson, S. B., \& Tudor-Locke, C. (2008). Comparison of cyclists' and motorists' utilitarian physical activity at an urban university. Preventive Medicine, 46(1), 77-79.

Spotswood, F., Chatterton, T., Tapp, A., \& Williams, D. (2015). Analyzing cycling as a social practice: An empirical grounding for behavior change. Transportation Research Part F: Traffic Psychology and Behavior, 29, 22-33.

Steinbach, R., Green, J., Datta, J., \& Edwards, P. (2011). Cycling and the city: A case study of how gendered, ethnic and class identities can shape healthy transport choices. Social Science \& Medicine, 72(7), 1123-1130.

Twaddle, H., Hall, F., \& Bracic, B. (2010). Latent bicycle commuting demand and effects of gender on commuter cycling and accident rates. Transportation Research Record: Journal of the Transportation Research Board, 2190, 28-36.

Verhoeven, H., Simons, D., Van Dyck, D., Van Cauwenberg, J., Clarys, P., De Bourdeaudhuij, I., de Geus, B., Vandelanotte, C., \& Deforche, B. (2016). Psychosocial and environmental correlates of walking, cycling, public transport and passive transport to various destinations in Flemish older adolescents. PLoS One, 11(1), e0147128.

Verplanken, B., Walker, I., Davis, A., \& Jurasek, M. (2008). Context change and travel mode choice: Combining the habit discontinuity and self-activation hypotheses. Journal of Environmental Psychology, 28(2), 121-127.

Wall, R., Devine-Wright, P., \& Mill, G. A. (2007). Comparing and combining theories to explain proenvironmental intentions: The case of commuting-mode choice. Environment and Behavior, 39(6), 731-753.

Wang, C.-H., Akar, G., \& Guldmann, J.-M. (2015). Do your neighbors affect your bicycling choice? A spatial probit model for bicycling to The Ohio State University. Journal of Transport Geography, 42, 122-130.

Whalen, K. E., Páez, A., \& Carrasco, J. A. (2013). Mode choice of university students commuting to school and the role of active travel. Journal of Transport Geography, 31, 132-142.

Willis, D. P., Manaugh, K., \& El-Geneidy, A. (2015). Cycling under influence: Summarizing the influence of perceptions, attitudes, habits, and social environments on cycling for transportation. International Journal of Sustainable Transportation, 9(8), 65-579.

Winship, C., \& Radbill, L. (1994). Sampling weights and regression analysis. Sociological Methods \& Research, 23(2), 230-257.

Winters, M., Brauer, M., Setton, E. M., \& Teschke, K. (2010). Built environment influences on healthy transportation choices: Bicycling versus driving. Journal of Urban Health, 87(6), 969-993.

Wuerzer, T., \& Mason, S. G. (2015). Cycling willingness: Investigating distance as a dependent variable in cycling behavior among college students. Applied Geography, 60, 95-106.

Zahabi, S. A. H., Chang, A., Miranda-Moreno, L. F., \& Patterson, Z. (2016). Exploring the link between the neighborhood typologies, bicycle infrastructure and commuting cycling over time and the potential impact on commuter GHG emissions. Transportation Research Part D: Transport and Environment, 47, 89-103. 